\title{
Role of Chest Ultrasound in Management of Shocked Patients
}

\author{
Esraa F. Abdel-Aal'1, Hamdy A. Mohammadien², Gamal M. Agamy³, Azza \\ M. Ahmed ${ }^{4}$
}

1.Teaching Assistant of Chest diseases and Tuberculosis, Faculty of Medicine, Sohag

University.

2.Professor of Chest diseases and Tuberculosis, Faculty of Medicine, Sohag University.

3.Professor of Chest diseases and Tuberculosis, Faculty of Medicine, Assuit University.

4.Lecturer of Chest diseases and Tuberculosis, Faculty of Medicine, Sohag University.

\begin{abstract}
Background:Care of the patient with shock is one of the most challenging issues in emergency medicine and critical care. Use of thoracic ultrasonography has gained a wider ground in emergency medicine and intensive care. So, lung ultrasound is being a basic application, allowing the assessment of urgent diagnoses and therapeutic decisions.

Aim of the work:This Study aimed to assess the value of chest ultrasound in differentiation between different types of shock for proper treatment.

Materials and Methods:Our prospective study was conducted on 68 shocked patients, 39 were males $(58 \%)$ and 29 were females $(41 \%)$ their age ranged from 20 to 85years with mean age 58 years. All patients were admitted to the Respiratory Intensive Care Unit (RICU) of Chest Department at Assuit University Hospital during the period from November 2016 to April 2017 and were evaluated for the cause of shock.We performed early bed-side chest sonographic examination.

Results: 68 shocked patients were included in the study. 30 patients were septic shock, 19 patients were obstructive shock, 11 patients were cardiogenic shock, 4 patients were hypovolemic shock,2 patients were mixed type of the shock, and 2 patients were not defined the causes of the shock. The study shows that there was a significant relationship between different types of shock and chest ultrasound finding $(\mathrm{P}=0.04) .14$ cases $(46.7 \%)$ with septic shock had consolidation.14 cases $(46.7 \%)$ with septic shock had pleural effusion and it was Para pneumonic. Also, we found 9 cases with pleural effusion $(47.3 \%)$ in obstructive shock due to pulmonary embolism. We found B-lines in $45.5 \%$ in cardiogenic shocked patients.

Also, there was a significant relationship between $\mathrm{PH}$ and $\mathrm{PaCO} 2$ different types of shock $(\mathrm{P}=0.04 \& 0.01$ respectively). We found that combined respiratory Acidosis and metabolic alkalosis was more in patients with septic shock.Also, we found that patients with cardiogenic shock had both acidosis and alkalosis disorders in equal.

Conclusion:We highlight the role of integrating chest ultrasound techniques in the physician resuscitation pathways to diagnose shock etiology, augment their clinical evaluation and guide resuscitation.
\end{abstract}

\section{Introduction}

Patients in shock have high mortality rates, and these rates are correlated to the amount and duration of hypotension. Therefore, diagnosis and initial care must be accurate and prompt to optimize patient outcomes. Failure to make the correct diagnosis and act appropriately can lead to potentially disastrous outcomes Jones et al., (2004).

Four types of shock exist, including hypovolemic, cardiogenic, distributive, and obstructive shock. Clinical 
assessment and classification of shock is extremely difficult in critically ill patients as there is sometimes an overlap between these types Strehlow.,(2010). Incorporation of bedside ultrasound in patients with undifferentiated shock allows for rapid evaluation of reversible causes of shock and improves accurate diagnosis in undifferentiated hypotension.

Thoracic ultrasound is a noninvasive and portable diagnostic tool which is highly indicated for an initial workup of emergency and respiratory care unit. The suspicion of a pneumothorax, pneumonia, pulmonary embolism can be quickly assessed using ultrasound Kreuteret al., (2014).

\section{Aim of the work:}

This Study aimed to assess the value of chestultrasoundin differentiation between different types of shock for propertreatment.

\section{Patients and methods:}

The study was conducted on68 shocked patients, their age ranged from 20 to 85years who were admitted to the medical emergency room, Respiratory Intensive Care Unit (RICU) of Chest Department at Assuit University Hospital during the period from November 2016 to April 2017 and were evaluated for the cause of shock.

\section{Inclusion criteria:}

The patient who was shocked with:

1. Hypotension (systolic BP $<90 \mathrm{~mm}$ $\mathrm{Hg}$ ) or a $30-\mathrm{mm} \mathrm{Hg}$ fall in baseline $\mathrm{BP}$, mean arterial pressure (MAP) $<60 \mathrm{mmHg}$ ).

2. Tachycardia (heart rate $>100$ ).

3. Tachypnea (respiratory rate $>22$ ).

Exclusion criteria:
1. Patients who were not shocked.

2. Patients with trauma history.

3. Children.

Initial clinical evaluation and immediate resuscitative interventions (intravenous (IV)-line, hydration, etc.) according to standard medical protocols were accomplished for all these patients. The admission diagnosis was formulated in a "standard" way, i.e. through medical history, ECG, laboratory investigations including ( $\mathrm{ABG}, \mathrm{CBC}$, Blood chemistry including liver function tests, renal function tests, serum electrolytes e.g. $\mathrm{Na}+, \mathrm{K}+, \mathrm{Cl}-, \mathrm{Ca}++$, prothrombin time and concentration and blood sugar and radiological examinations including (chest and / or abdomen X-ray and / or chest and / or abdomen CT).

Meanwhile, equipment for bed-side sonographic examination was prepared without any delay or interruption in patients' initial care. We examined the patients in a supine to $30^{\circ}$ upright position with two-dimensional grayscale bedside sonography. A Medison SonoAceR3 ultrasound system with 2$8 \mathrm{MHz}$ curvilinear and 5-12 $\mathrm{MHz}$ linear probes was used.

\section{Statistical analysis:}

The collected data were organized, tabulated and statistically analyzed, using STATA intercooled version 14.2. Mean, standard deviation, frequency and percentage were used as descriptive; chi square test $\left(\mathrm{X}^{2}\right)$ was used for testing significance of observed differences.Graphs were produced by using Excel or STATA program.P value was considered significant if it was less than 0.05 . 


\section{Results}

\begin{tabular}{|l||l||l||}
\hline Variable & Number & Percent \\
\hline \hline Age (year) & \multicolumn{2}{|l||}{} \\
Mean \pm SD & $57.8 \pm 18.2$ & \\
Median (range) & $63(20-92)$ & \\
\hline \hline Gender & \multicolumn{2}{|l||}{} \\
Females & 29 & $(42.7 \%)$ \\
Males & 39 & $(57.3 \%)$ \\
\hline \hline Occupation & & \\
Housewife & 27 & $(39.6 \%)$ \\
Farmer & 16 & $(23.5 \%)$ \\
Worker & 14 & $(20.6 \%)$ \\
Teacher & 5 & $(7.4 \%)$ \\
Employer & 4 & $(5.9 \%)$ \\
Lawyer & 1 & $(1.5 \%)$ \\
Policeman & 1 & $(1.5 \%)$ \\
\hline \hline Smoking status & & \\
Currant & 13 & $(19.1 \%)$ \\
Ex-smoker & 20 & $(28.4 \%)$ \\
Non-smoker & 35 & $(52.5 \%)$ \\
\hline \hline Smoking index & & \\
Mild & 2 & $(6 \%)$ \\
Moderate & 13 & $(39 \%)$ \\
Sever & 18 & $(54 \%)$ \\
\hline
\end{tabular}

Table 1: Demographic characteristics of the studied populations (68)

Table (1): shows; the mean age for the studied population was 57.8 years. 29 cases $(44.7 \%)$ were females and 39 cases $(57.3 \%)$ were males.35 cases $(52.5 \%)$ were nonsmokers, 13 cases $(19.1 \%)$ were smokers and 14 cases $(28.4 \%)$ were ex-smokers.13 cases (39\%) were moderate smokers, 18cases $(41.5 \%)$ were heavy smokers and 2cases $(1.89 \%)$ were mild smoker. 
SOHAG MEDICAL JOURNAL

Vol. 23 No.1 Jan 2019

\begin{tabular}{|c|c|c|c|c|c|c|c|}
\hline Variable & $\begin{array}{l}\text { Cardiogenic } \\
\mathrm{N}=11\end{array}$ & $\begin{array}{l}\text { Hypovolemic } \\
\mathrm{N}=4\end{array}$ & $\begin{array}{l}\text { Obstructive } \\
\text { N=19 }\end{array}$ & $\begin{array}{l}\text { Septic } \\
\mathbf{N}=30\end{array}$ & $\begin{array}{l}\text { Mixed } \\
\mathrm{N}=2\end{array}$ & $\begin{array}{l}\text { Not defined } \\
\mathrm{N}=2\end{array}$ & $\begin{array}{l}P \\
\text { value }\end{array}$ \\
\hline $\begin{array}{l}\text { PH } \\
\text { Mean } \pm \text { SD } \\
\text { Median } \\
\text { (range) }\end{array}$ & $\begin{array}{l}7.3 \pm 0.1 \\
7.3(7.1-7.5)\end{array}$ & $\begin{array}{l}7.3 \pm 0.2 \\
7.3(7.0-7.4)\end{array}$ & $\begin{array}{l}7.4 \pm 0.1 \\
7.4 \\
7.5)\end{array}$ & $\begin{array}{l}7.3 \pm 0.1 \\
7.3(6.9-7.5)\end{array}$ & $\begin{array}{l}7.2 \pm 0.1 \\
7.2 \quad(7.1- \\
7.3)\end{array}$ & $\begin{array}{l}7.4 \pm 0.1 \\
7.4 \quad(7.4- \\
7.5)\end{array}$ & 0.04 \\
\hline $\begin{array}{l}\text { PaCO2 } \\
(\mathbf{m m H g}) \\
\text { Mean } \pm \text { SD } \\
\text { Median } \\
\text { (range) }\end{array}$ & $\begin{array}{l}58.9 \pm 26.9 \\
50(27-110)\end{array}$ & $\begin{array}{l}67.8 \pm 23.6 \\
60.5 \\
102)\end{array}$ & $\begin{array}{l}43.6 \pm 22.3 \\
35(20-91)\end{array}$ & $\begin{array}{l}64.7 \pm 23.4 \\
64.5 \\
107)\end{array}$ & $\begin{array}{l}47.5 \pm 17.7 \\
47.5 \quad(35- \\
60)\end{array}$ & $\begin{array}{l}21.5 \pm 6.4 \\
21.5 \quad(17- \\
26)\end{array}$ & 0.01 \\
\hline $\begin{array}{l}\text { PaO2 }(\mathbf{m m H g} \\
\text { ) } \\
\text { Mean } \pm \text { SD } \\
\text { Median } \\
\text { (range) }\end{array}$ & $\begin{array}{l}57.1 \pm 15.5 \\
57(38-90)\end{array}$ & $\begin{array}{l}64.3 \pm 20.5 \\
57.5(49-93)\end{array}$ & $\begin{array}{l}56.1 \pm 10.4 \\
54(41-82)\end{array}$ & $\begin{array}{l}57.8 \pm 13.0 \\
52(40-90)\end{array}$ & $\begin{array}{l}55.0 \pm 11.3 \\
55(47-63)\end{array}$ & $\begin{array}{l}65.0 \pm 7.1 \\
65(60-70)\end{array}$ & 0.85 \\
\hline $\begin{array}{l}\text { SaO2\% } \\
\text { Mean } \pm \text { SD } \\
\text { Median } \\
\text { (range) }\end{array}$ & $\begin{array}{l}84.4 \pm 9.3 \\
83(68-99)\end{array}$ & $\begin{array}{l}83.0 \pm 12.4 \\
85(67-95)\end{array}$ & $\begin{array}{l}83.2 \pm 9.6 \\
85(60-95)\end{array}$ & $\begin{array}{l}82.6 \pm 11.1 \\
83.5(50-99)\end{array}$ & $\begin{array}{l}78.0 \pm 18.4 \\
78(65-91)\end{array}$ & $\begin{array}{l}89.5 \pm 7.8 \\
89.5 \quad(84- \\
95)\end{array}$ & 0.92 \\
\hline $\begin{array}{l}\mathbf{H C O 3} \\
(\mathbf{m E q} / \mathbf{L}) \\
\text { Mean } \pm \text { SD } \\
\text { Median } \\
\text { (range) }\end{array}$ & $\begin{array}{l}26 \pm 7.5 \\
27(11-38)\end{array}$ & $\begin{array}{l}25.8 \pm 5.1 \\
26.5(20-30)\end{array}$ & $\begin{array}{l}23.9 \pm 7.2 \\
22(7-34 \%)\end{array}$ & $\begin{array}{l}27.4 \pm 9 \\
26(13-48)\end{array}$ & $\begin{array}{l}28.5 \pm 16.3 \\
28.5 \quad(17- \\
40)\end{array}$ & $\begin{array}{l}24.0 \pm 2.8 \\
24.0 \quad(22- \\
26)\end{array}$ & 0.84 \\
\hline
\end{tabular}

Table 2: Comparison of arterial blood gases parameters among different types of shock

Table 2: shows: that there was statistically significant relationship between $\mathrm{PH}$ and different types of shock $(\mathrm{P}=0.04)$. There was a statistically significant relationship between $\mathrm{PaCO} 2$ and different types of shock $(\mathrm{P}=0.01)$. Acidosis was more obvious with septic and hypovolemic shock. There was nostatistically significant relationship between $\mathrm{PaO} 2, \mathrm{SaO} 2 \%, \mathrm{HCO} 3$ and different types of shock $\mathrm{P}=0.85,0.92,0.84$ respectively. 
SOHAG MEDICAL JOURNAL

Vol. 23 No.1 Jan 2019
Role of Chest Ultrasound in Management

Esraa F. Abdel-Aal.et al

\begin{tabular}{|c|c|c|c|c|c|c|c|}
\hline Variable & $\begin{array}{l}\text { Cardiogenic } \\
\mathrm{N}=11\end{array}$ & $\begin{array}{l}\text { Hypovolemic } \\
\mathrm{N}=\mathbf{4}\end{array}$ & $\begin{array}{l}\text { Obstructive } \\
\mathrm{N}=19\end{array}$ & $\begin{array}{l}\text { Septic } \\
\text { N=30 }\end{array}$ & \begin{tabular}{|l} 
Mixed \\
$\mathrm{N}=2$
\end{tabular} & $\begin{array}{l}\text { Not } \\
\text { defined } \\
\mathrm{N}=2\end{array}$ & $\begin{array}{l}\mathbf{P} \\
\text { value }\end{array}$ \\
\hline Hyperinflation & $1(10 \%)$ & $2(50 \%)$ & $4(33.3 \%)$ & $8(38.1 \%)$ & $1(100 \%)$ & 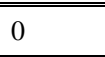 & \multirow{9}{*}{0.003} \\
\hline Consolidation & 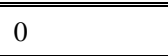 & 0 & 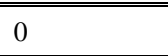 & $6(28.6 \%)$ & 0 & 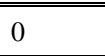 & \\
\hline Cardiomegaly & $8(80 \%)$ & 20 & $1(8.33 \%)$ & 10 & $\begin{array}{l}0 \\
\end{array}$ & 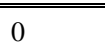 & \\
\hline Plural effusion & 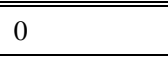 & $1(25 \%)$ & $2(16.7 \%)$ & $5(23.8 \%)$ & 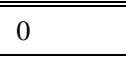 & 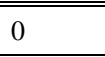 & \\
\hline $\begin{array}{l}\text { Raised copula of } \\
\text { diaphragm }\end{array}$ & 0 & 0 & $2(16.7 \%)$ & 0 & 0 & 0 & \\
\hline Reticular shadow & $1(10)$ & $1(25 \%)$ & 0 & 0 & 0 & 0 & \\
\hline "Cannon ball & 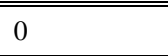 & 0 & $1(8.3 \%)$ & 0 & 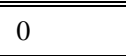 & 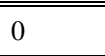 & \\
\hline Hilar shadow & 0 & 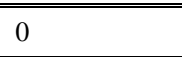 & 0 & $1(4.8 \%)$ & $\begin{array}{l}0 \\
\end{array}$ & 0 & \\
\hline Normal & 0 & 0 & $2(16.7 \%)$ & 0 & 0 & 0 & \\
\hline
\end{tabular}

Table 3: Comparison among different types of shock according to chest $x$-ray finding

Table 3: shows that there was statistically significant relationship between different types of shock and chest x-ray finding of the studied population.6 cases with septic shock had consolidation .8cases with cardiogenic shock had cardiomegaly.

\begin{tabular}{|l||l|}
\hline Chest US finding & Number (\%) \\
\hline \hline Normal & $6(8.8 \%)$ \\
Consolidation & $21(30.9 \%)$ \\
Effusion & $29(42.6 \%)$ \\
B lines & $6(8.8 \%)$ \\
Pneumothorax & $2(2.9 \%)$ \\
Lung mass & $1(1.5 \%)$ \\
Hypoechoic lesion suggestive pulmonary embolism & $2(2.9 \%)$ \\
Pyopneumothorax & $1(1.5 \%)$ \\
\hline
\end{tabular}

Table 4: Chest US finding in studied population (68)

Table 4: shows that 29 cases $(42.6 \%)$ had pleural effusion .21 cases $(30.9 \%)$ had consolidation ,6 cases $(8.8 \%)$ had B-lines, 6 cases were normal 2 cases $(2.9 \%)$ had pneumothorax, 2cases $(2.9 \%)$ had Hypoechoic lesion suggestive pulmonary embolism, 1 case $(1.5 \%)$ had Pyopneumothorax and another case had lung mass. 
SOHAG MEDICAL JOURNAL

Vol. 23 No.1 Jan 2019

Role of Chest Ultrasound in Management

Esraa F. Abdel-Aal.et al

\begin{tabular}{|c|c|c|c|c|c|c|c|}
\hline Chest US finding & $\begin{array}{l}\text { Cardiogenic } \\
\mathrm{N}=11\end{array}$ & $\begin{array}{l}\text { Hypovolemic } \\
\mathrm{N}=4\end{array}$ & $\begin{array}{l}\text { Obstructive } \\
\text { N=19 }\end{array}$ & $\begin{array}{l}\text { Septic } \\
\mathrm{N}=30\end{array}$ & $\begin{array}{l}\text { Mixed } \\
\mathrm{N}=2\end{array}$ & $\begin{array}{l}\text { Not } \\
\text { defined } \\
\mathrm{N}=2\end{array}$ & $\begin{array}{l}\mathbf{P} \\
\text { value }\end{array}$ \\
\hline Normal & $2(18.2 \%)$ & $1(25 \%)$ & $2(10.5 \%)$ & $1(3.3 \%)$ & 0 & 0 & \multirow{7}{*}{0.04} \\
\hline Consolidation & $1(9.1 \%)$ & $1(25 \%)$ & $3(15.8 \%)$ & $14(46.7 \%)$ & $\begin{array}{l}1 \\
(50 \%)\end{array}$ & $\begin{array}{l}1 \\
(50 \%)\end{array}$ & \\
\hline Effusion & $3(27.3 \%)$ & $1(25 \%)$ & $9(47.3 \%)$ & $14(46.7 \%)$ & $\begin{array}{l}1 \\
(50 \%)\end{array}$ & $\begin{array}{l}1 \\
(50 \%)\end{array}$ & \\
\hline B lines & $5(45.5 \%)$ & $1(25 \%)$ & 0 & 0 & 0 & 0 & \\
\hline Pneumothorax & 0 & 0 & $2(10.5 \%)$ & 0 & 0 & 0 & \\
\hline Lung mass & 0 & 0 & $1(5.3 \%)$ & 0 & 0 & 0 & \\
\hline $\begin{array}{lrr}\text { Hypo } & \text { echoic } & \text { lesion } \\
\text { suggest } & \text { Pulmonary } \\
\text { embolism } & & \end{array}$ & 0 & 0 & $2(10.5 \%)$ & 0 & 0 & 0 & \\
\hline Pyopneumothorax & 0 & 0 & 0 & $1(3.3 \%)$ & 0 & 0 & \\
\hline
\end{tabular}

Table 5:Comparison among different types of shock according to chest US finding

Table 5:shows that there wasstatistically significant relationship between different types of shock and chest US finding (p: 0.04). 14 cases (46.7\%) of patients with septic shock had consolidation.14 cases $(46.7 \%)$ of patients with septic shock had pleural effusion .5 cases $(45.5 \%)$ of patients with cardiogenic shock had B lines .2 cases $(10.5 \%)$ of patients with obstructive shock had pneumothorax and another 2cases had Hypoechoic lesion suggest Pulmonary embolism.

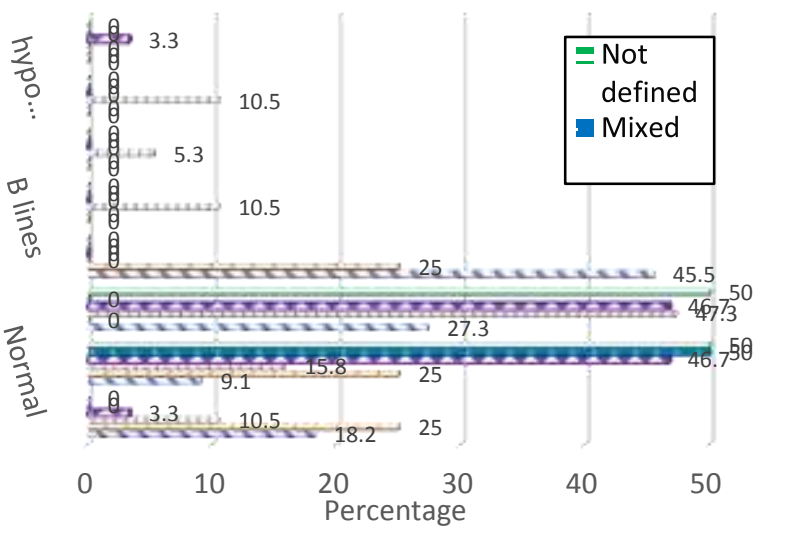

Figure 1: Comparison among different types of shock according to Chest US finding 


\section{Discussion}

Lung ultrasound allows the intensivist to quickly answer to most critical situations. Not only pleural effusion but also pneumothorax, alveolar consolidation, and interstitial syndrome. Our study shows that, there was a significant relationship between different types of shock and chest ultrasound finding $(\mathrm{P}=0.04) .14$ cases $(46.7 \%)$ with septic shock had consolidation.14 cases $(46.7 \%)$ with septic shock had pleural effusion and it was Para pneumonic. This result agreed with Vignon Repessé et al.,(2016) who found that chest ultrasonographic findings of patients sustaining severe pneumonia associated with septic shock show lung consolidation and pleural effusion. Also,

Lichtenstein and Meziere.,(2008) found that lung ultrasound is an excellent tool to detect lung consolidation and it is the most accurate method for detecting pleural effusion. Transudates are mostly echo poor whereas exudates are often echo rich Sajadiehet al., (2004).

we found 5 cases $(45.5 \%)$ with cardiogenic shock had B -lines. This result agreed with Volpicelli et al., (2008) who found that bedside chest ultrasound of acute decompensated heart failure patients show B- line pattern.Reissig et al.,(2011) found that in acute clinical conditions, more frequently, bilateral and diffuse B-lines are an ultrasonographic sign of increased extravascular lung water. Therefore, the presence of multiple B-lines identifies the "wet lung" while the absence, the " dry lung".

we found 2 cases had pneumothorax and this was the cause of obstructive shockand this result supported by Lichtenstein et al., (2008) who showed thatlung ultrasound is the best tool for bedside diagnosis of pneumothorax specially in critically ill patients and bedridden.

This study reports that there was a significant relationship between $\mathrm{PH}$ and $\mathrm{PaCO} 2$ different types of shock $(\mathrm{P}=0.04 \& 0.01$ respectively). we found that combined respiratory Acidosis and metabolic alkalosis was more in patients with septic shock and this result disagreed with Kellum et al., (2004) who found that metabolic acidosis is a common problem in patients with sepsis and other forms of critical illness and is associated with poor outcome and acidosis may occur because of increases in arterial $\mathrm{PaCO} 2$ (respiratory acidosis) or from a variety organic or inorganic fixed acid (metabolic acidosis). this can be explained that most of our patients had chronic respiratory diseases. This result agreed with Allan et al., (2017)whoreported that in patients with sepsis and trauma metabolic alkalosis is most often a result of treatment given to correct hypotension, shock and acidosis. In these situations, patients are often given large doses of citrated blood, Ringer's acetate and sometimes bicarbonate. In addition, there may be gastrointestinal losses due to nasogastricemptying, vomiting, diuretics, diarrhea and antibiotic.

Also, we found that patients with cardiogenic shock had both acidosis and alkalosis disorders in equal this result agreed with Park et al., (2015) who proved that in high-risk AHF patients, the most common acid-base imbalance is alkalosis. Acidosis is observed in poor prognostic patients and so it is a significant predictor of mortality. This can be explained as in AHF patients with cardiogenic pulmonary edema, the cardiac congestion leads to pulmonary 
edema with impaired gas exchange (hypoxemia and hypercapnia) and the low cardiac output to a decreased tissue perfusion lead to metabolic acidosis Gehlbach \& Geppert., (2004).

\section{Conclusion}

Physicians caring for critical patients should strongly consider integrating chest ultrasound into their resuscitation pathways to augment their clinical evaluation and guide resuscitation.

\section{References}

1-Jones Alan, Lyn Aborn, and Jeffrey Kline (2004): Severity of Emergency Department Hypotension Predicts Adverse Hospital Outcome. Shock 22 (5):410-14.

2-Strehlow Matthew (2010): Early Identification of Shock in Critically Ill Patients. Emergency Medicine Clinics of North America 28 (1): 57-66.

3-Kreuter Michael and Gebhard Mathis (2014): Emergency ultrasound of the chest." Respiration 87(2): 89-97.

4-Vignon Philippe, Xavier Repessé, AntoineVieillard-baron and Eric Maury (2016): Critical Care Ultrasonography in Acute Respiratory Failure. Critical Care :20(228): 1-11.

5- Lichtenstein Daniel, and Gilbert Meziere (2008):Relevance of lung ultrasound in the diagnosis of acute respiratory failure: The BLUE Protocol. Chest 134: 117-125.
6-Sajadieh, Hamidreza, et al. (2004): Ultrasound as an alternative to aspiration for determining the nature of pleural effusion especially in older people. Annals of the New York Academy of Sciences 1019.1: 585-592.

7-Volpicelli Giovanni, Valeria Caramello, Luciano Cardinale, Alessandro Mussa, Fabrizio Bar, and Mauro Frascisco (2008): Bedside Ultrasound of the Lung for the Monitoring of Acute Decompensated Heart Failure. American Journal of Emergency Medicine; 26:585591.

8-Reissig, Angelika, Roberto Copetti, and Claus Kroegel (2011): Current role of emergency ultrasound of the chest. Critical care medicine 39.4: 839845.

9-Kellum et al., (2004): Metabolic Acidosis in Patients with Sepsis: Epiphenomenon or Part of the Pathophysiology? Critical Care and Resuscitation 6: 197-203.

10-Jazrawi Allan, Jan Miller, Amir Baigi and Michelle Chew (2017): Alkalosis in Critically Ill Patients with Severe Sepsis and Septic Shock. Plos One 12(1): 1-10.

11- Park Jin Joo, Dong-Ju Choi et al., (2014): The Prognostic Value of Arterial Blood Gas Analysis in Acute Heart Failure Patients. Journal of Cardiac Failure 20 (10): 169.

12-Gehlbach Brian and Eugene Geppert (2004): The Pulmonary Manifestations of Left Heart Failure. Chest Journal 125 (2) :669-82. 